\title{
Prediction of the fraction of water bypassed to ECBD due to interaction of air crossflow
}

\author{
Y. S. Bang \& D. H. Yoon \\ Korea Institute of Nuclear Safety, Korea
}

\begin{abstract}
An interaction of a jet-shaped subcooled water flow with a lateral steam flow in saturated and/or superheated state can be found at the downcomer of the reactor vessel of nuclear power plants during the reflood phase of loss-of-coolantaccident (LOCA). These phenomena may increase the amount of water bypassed toward the break outside the vessel and may have an impact on peak cladding temperature which is one of the key safety parameters of the reactor safety, especially for the plants which has an emergency core cooling system (ECCS) injected to the reactor vessel downcomer directly (DVI). A device 'ECBD (ECCS core barrel duct)', a duct which is attached to the core barrel wall and has a horizontal opening for the ECC water jet incoming and an vertical outlet to the lower part of the downcomer, has been proposed in the advanced ECCS design to improve the adverse effect of ECC water bypass. The present study aims at predicting the phenomena using computational fluid dynamic (CFD) analysis based on the simple air-water duct experiment and the interaction with a gas in terms of the fraction of water bypassing the ECBD. The assumed velocities of the air and the water are ranged to be close to the actual accident situation. To simulate the air-water two-phase flow, the homogeneous model considering the surface tension and volume fraction at each phase is used. The effect of turbulence during the interaction, the SST turbulence model is used. From the result of the CFD calculation, the form loss factor at the opening of the ECBD is derived for a reasonable calculation of the one-dimensional two-phase system code to be used in the accident analysis.
\end{abstract}

Keywords: computational fluid dynamics, cross flow, direct vessel injection, emergency core barrel duct. 


\section{Introduction}

In contrast to the conventional emergency core cooling system (ECCS) injected to the cold legs of the reactor (CLI), the direct vessel injection (DVI) type ECCS was adopted in APR1400 (Advanced Power Reactor of 1400MWe) and APR+ (Advanced Power Reactor Plus of $1500 \mathrm{MWe}$ ) by Korea Hydro and Nuclear Power Co. (KHNP) [1], where the ECCS water is directly injected into the downcomer of the reactor vessel through the DVI nozzle located at higher elevation than the cold leg one. The difference between CLI and DVI may involve the amount of the ECCS water which does not reach the reactor core among the injected one, i.e. ECC bypass, and its duration. Especially for DVI, it has been concerned that the ECC water injected through the DVI nozzle may be bypassed out to the broken cold leg more easily than that of the cold leg injection (CLI) during the reflood phase in the event of a large break loss of coolant accident (LBCOCA).

From the research by USNRC [2], it was reported that several thermalhydraulic phenomena in the downcomer such as the entrainment of ECC water by the break flow from the reactor vessel and the loss of water head in the downcomer by the hot wall effect might be potential reasons for the ECC water bypass. The ECC bypass during the reflood phase can also be affected by the steam flow from the intact cold legs. Steam is significantly generated from the core, accelerated by the heat addition when passing through the steam generator, and injected into the reactor vessel downcomer. As a result, a lateral flow to the downflow of ECC water (i.e. cross flow) may be established and a strong interaction between both flows may be expected within the downcomer region.

A new DVI+ design for APR+ has been proposed by Kwon et al. [3] as shown in Figure 1.
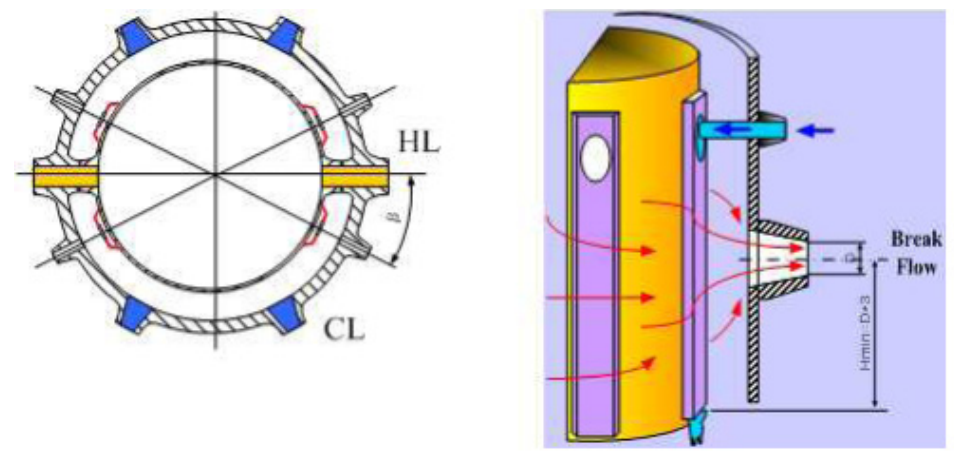

Figure 1: Configuration of ECBD.

In the DVI+ design, the rectangular shaped emergency core barrel duct (ECBD) is attached to the surface of the core barrel at the opposite the DVI nozzle exit, to reduce the bypass fraction of the ECC water caused by the steam 
cross flow in the downcomer. Since the bypass fraction of the ECC water into the reactor core by the cross flow is an important safety issue, the effect of cross flow and the performance of the ECBD need to be evaluated.

In the present study, computational fluid dynamics (CFD) simulation was conducted in order to confirm the fraction of inflow into the ECBD among the ECC water and to evaluate the performance of the ECBD. For this purpose, a simplified air-water test by Kwon et al. [4] was selected for a validation of the CFD analysis (Figure 2). Sensitivity study was conducted for the different air cross flows forced from the side of the outer duct. Also, the pressure loss factor at the junction of ECBD inlet was derived from the CFD results as a function of Reynolds number of the cross flow. Since, the loss factor is commonly used in the system thermal-hydraulic codes for safety analysis, the performance of ECBD can be practically considered in the accident analysis by use of the result of the present study.

\section{Experiment and numerical simulation}

The full-scale ECBD test facility used in the present prediction was shown in Figure 2 [4]. All dimensions in the figure are mm. In the experiment, a steadystate water injection to the downcomer with ECBD was simulated to evaluate the bypass fraction of ECC water to the ECBD.

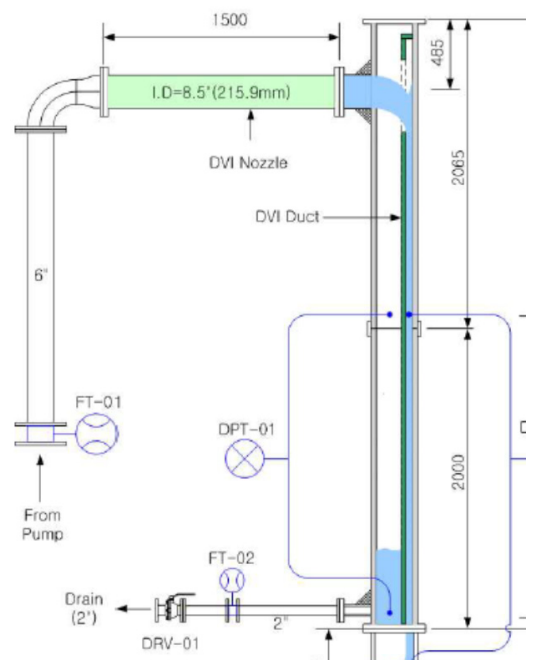

Figure 2: Full scale ECBD experiment facility.

For the CFD simulation of this problem, the homogeneous governing equations for steady Reynolds-Averaged Navier-Stokes (RANS) analysis for incompressible two-fluid flow were considered as follows: 


$$
\begin{gathered}
\frac{\partial}{\partial t}\left(\gamma_{\alpha} \rho_{\alpha}\right)+\nabla \cdot\left(\gamma_{\alpha} \rho_{\alpha} \mathbf{U}\right)=0 \\
\frac{\partial}{\partial t}(\rho \mathbf{U})+\nabla \cdot(\rho \mathbf{U} \otimes \mathbf{U})=-\nabla P+\nabla \cdot\left[\mu\left(\nabla \mathbf{U}+(\nabla \mathbf{U})^{T}\right)-\rho \overline{\mathbf{u}^{\prime} \mathbf{u}^{\prime}}\right]+\mathbf{S}_{\mathbf{M}} \\
\rho=\sum_{\alpha=1}^{2} \gamma_{\alpha} \rho_{\alpha} \quad \mu=\sum_{\alpha=1}^{2} \gamma_{\alpha} \mu_{\alpha}
\end{gathered}
$$

where $\gamma_{\alpha}, \rho, \mu, S_{M}$ and $\mathbf{U}$ denote the volume fraction, density, viscosity, momentum source and velocity vector, respectively. The summation of volume fractions $\Sigma \gamma_{\alpha}$ is 1. The shear stress transport (SST) turbulence model [5] was used for turbulence closure. To consider the two-phase flow of air and water, a homogenous model considering the surface tension and volume fraction at each phase was used. For the boundary conditions, a uniform velocity was specified at the DVI nozzle inlet. The opening conditions were applied at the downcomer exit and ECBD outlet, respectively. In the case of considering the air cross flow, a uniform air velocity was assumed at the side inlet of the outer duct, and the opening condition was used at the other side outlet. A no-slip condition was specified at the whole wall.

Figure 3 shows the CFD model used in this study. A hexahedron-structured mesh was used for the numerical analysis, and the total number of elements is approximately 500,000.

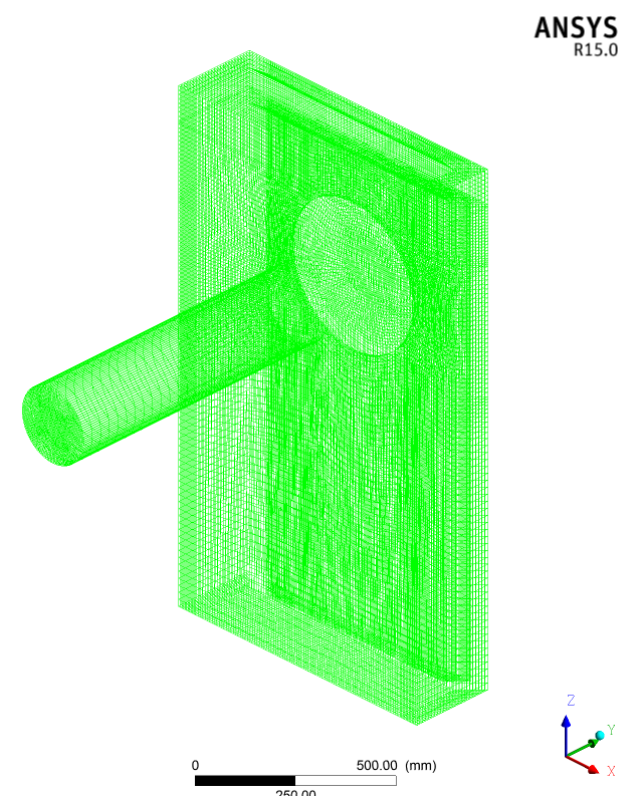

Figure 3: Calculation Mesh of ECBD experiment. 


\section{Results and discussion}

\subsection{Case without the air cross flow}

At the experiment, water was injected through the DVI nozzle into the outer duct simulating the part of the reactor downcomer of the plant. The fraction of inflow to ECBD was measured for two cases of velocity of the water at the nozzle, $1.6 \mathrm{~m} / \mathrm{s}$ and $1.757 \mathrm{~m} / \mathrm{s}$, respectively, which were the typical range obtained from the accident analysis by [1]. In the present study, cases of lower velocity as well as the test cases were calculated to investigate the flow characteristics and inflow fraction into the ECBD when the inlet velocity of the DVI nozzle is decreased.

Figure 4 compares the flow patterns of the experiment [4] and the current CFD results when the inlet velocity of the DVI nozzle $\left(V_{D V I}\right)$ is $1.584 \mathrm{~m} / \mathrm{s}$. It is observed that the water stream sagging vertically by gravitational force and the pattern of the flow hitting and climbing up the wall are similar to the experiment.

Normally when a flow is discharged from a horizontal duct or pipe, it was reported that the flow pattern is changed to open-channel flow by the balance of gravity force and the inertial force (Ahmad and Azamathulla [6]). Figure 5 shows iso-surfaces of the water volume fraction with decreasing $V_{D V I}$. It is clearly observed that the flow pattern changes to the free surface flow as $V_{D V I}$ decreases. As noted in reference [6], the end-depth of the open-channel flow through a horizontal pipe decreases with the Froude number. The present study similarly shows that the end-depth decreases with $V_{D V I}$.
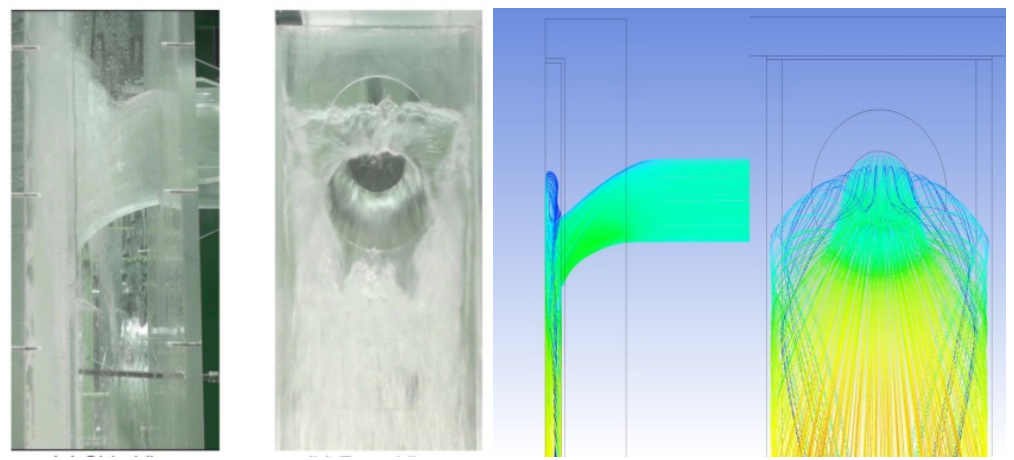

Figure 4: Comparison of flow pattern between experiment and calculation at $V_{D V I}=1.584 \mathrm{~m} / \mathrm{s}$.

Figure 6 shows the contours of the superficial water velocity at the DVI nozzle exit for $V_{D V I}=1.757 \mathrm{~m} / \mathrm{s}, 1.584 \mathrm{~m} / \mathrm{s}, 1.0 \mathrm{~m} / \mathrm{s}$ and $0.5 \mathrm{~m} / \mathrm{s}$. The water flow from the DVI nozzle inlet to the exit of the nozzle is strongly affected by the gravitational force as it reaches the downcomer. This yields the higher velocity distribution at the lower part of the DVI nozzle, as shown in Figure 6. 


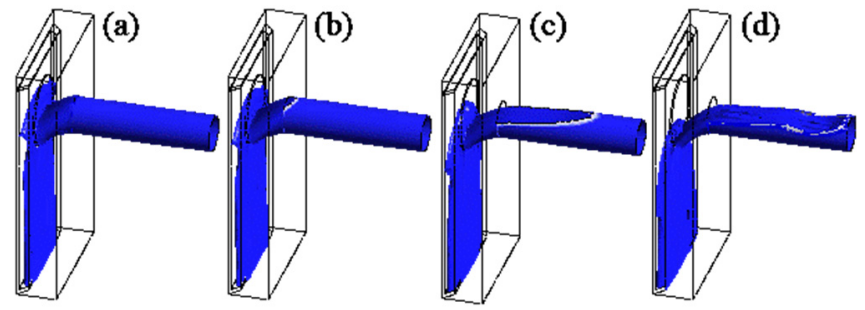

Figure 5: Iso-surfaces of water volume fraction: (a) $V_{D V I}=1.757 \mathrm{~m} / \mathrm{s}$, (b) $V_{D V I}=1.584 \mathrm{~m} / \mathrm{s}$, (c) $V_{D V I}=1.0 \mathrm{~m} / \mathrm{s}$, (d) $V_{D V I}=0.5 \mathrm{~m} / \mathrm{s}$.

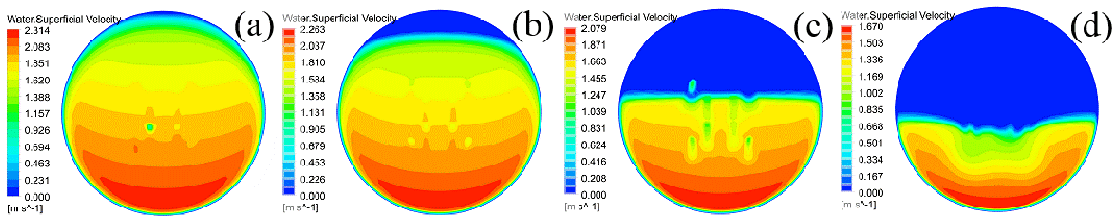

Figure 6: Contours of water superficial velocity at DVI nozzle exit: (a) $V_{D V I}=1.757 \mathrm{~m} / \mathrm{s}$, (b) $V_{D V I}=1.584 \mathrm{~m} / \mathrm{s}$, (c) $V_{D V I}=1.0 \mathrm{~m} / \mathrm{s}$, (d) $V_{D V I}=0.5 \mathrm{~m} / \mathrm{s}$.

Table 1 presents the fraction of water bypassing the ECBD with decreasing DVI inlet velocity. At the experiment [4], the water fractions not inflowing to ECBD were measured to be $3 \sim 4 \%$ when $V_{D V I}=1.584 \mathrm{~m} / \mathrm{s}$ and $1.757 \mathrm{~m} / \mathrm{s}$. The present CFD result provided those fractions similar to the experiment. When $V_{D V I}$ is $1.0 \mathrm{~m} / \mathrm{s}$ or higher, most of the flow is injected into the ECBD; however, approximately $40 \%$ is not injected when $V_{D V I}$ is $0.5 \mathrm{~m} / \mathrm{s}$. It means that the vertical deflection of the ECC water jet by gravity increases as the DVI inlet velocity decreases, and reaches up to the certain level, then the inflow rate into the ECBD rapidly decreases. When the DVI inlet velocity decreases, the flow gradually changes to an open-channel flow, and the averaged velocity of water at the DVI nozzle exit becomes higher than the DVI inlet velocity. This contributes to increase the ECBD inflow rate of the safety injection water.

Table 1: Water fraction outside of ECBD.

\begin{tabular}{|c|c|c|c|c|}
\hline$V_{D V I}$ & $0.5 \mathrm{~m} / \mathrm{s}$ & $1.0 \mathrm{~m} / \mathrm{s}$ & $1.584 \mathrm{~m} / \mathrm{s}$ & $1.757 \mathrm{~m} / \mathrm{s}$ \\
\hline Present & $40.8 \%$ & $3.6 \%$ & $5.9 \%$ & $4.2 \%$ \\
\hline Experiment [4] & - & - & $3.181 \%$ & $4.013 \%$ \\
\hline
\end{tabular}

\subsection{Case with the air cross flow}

As noted previously, when ECC water is injected through the DVI nozzle during an LBLOCA, a strong steam cross flow may occur in the downcomer. For this 
aspect, four different velocities of the air cross flow $\left(V_{\text {air }}\right)$ were considered: 5,10 , 20 , and $30 \mathrm{~m} / \mathrm{s}$, which are in the range expected during the LBLOCA reflood phase.

Figure 7 shows the contours of the water superficial velocity for each air flow velocity at the DVI nozzle exit when $V_{D V I}$ is $1.757 \mathrm{~m} / \mathrm{s}$. It is clearly shown that the velocity distribution of water is significantly affected by the momentum of the air cross flow and gravitational force near the DVI nozzle exit. In addition, it is confirmed through the slope of the contour lines that the momentum of the air cross flow affects greatly at the upper part of the DVI nozzle more strongly than the lower part because the water velocity is relatively low.

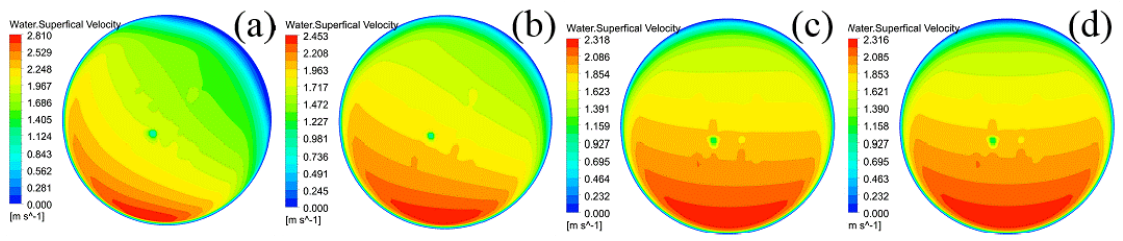

Figure 7: Contours of water superficial velocity at DVI nozzle exit with $V_{D V I}=1.757 \mathrm{~m} / \mathrm{s}$ : (a) $V_{\text {air }}=30 \mathrm{~m} / \mathrm{s}$, (b) $V_{\text {air }}=20 \mathrm{~m} / \mathrm{s}$, (c) $V_{\text {air }}=10 \mathrm{~m} / \mathrm{s}$, (d) $V_{\text {air }}=5 \mathrm{~m} / \mathrm{s}$.

Figure 8 presents the three-dimensional streamlines for the water superficial velocity at each air cross flow velocity on the $\mathrm{x}-\mathrm{y}$ plane and $\mathrm{x}-\mathrm{z}$ planes. It can be stated that most of the ECC water is not directed into the ECBD inlet and is discharged to the opposite outlet together with the air cross flow as the air cross flow is increased. In addition, it is also shown that the inflow rate into ECBD increases as the air cross flow velocity gradually decreases.
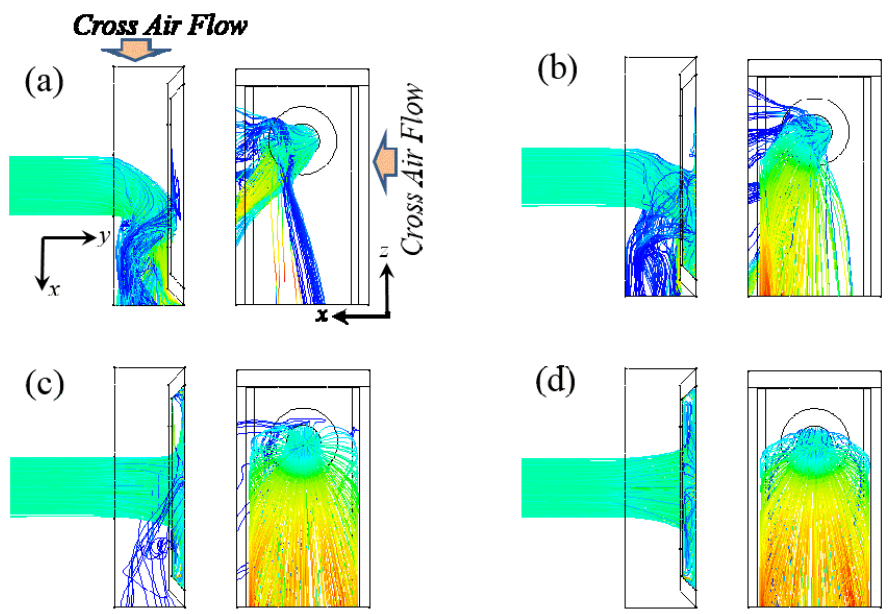

Figure 8: Streamlines of water superficial velocity with $V_{D V I}=1.757 \mathrm{~m} / \mathrm{s}$ : (a) $V_{\text {air }}=30 \mathrm{~m} / \mathrm{s}$, (b) $V_{\text {air }}=20 \mathrm{~m} / \mathrm{s}$, (c) $V_{\text {air }}=10 \mathrm{~m} / \mathrm{s}$, (d) $V_{\text {air }}=5 \mathrm{~m} / \mathrm{s}$. 
Figure 9 presents the water fraction not inflowing to the ECBD (bypass fraction) with the Reynolds number $\left(\operatorname{Re}_{\text {cross }}\right)$ of the air cross flow, which is nondimensionalized by the downcomer gap size and the air cross flow velocity. The bypass fraction was found to increase dramatically with $R e_{\text {cross }}$.

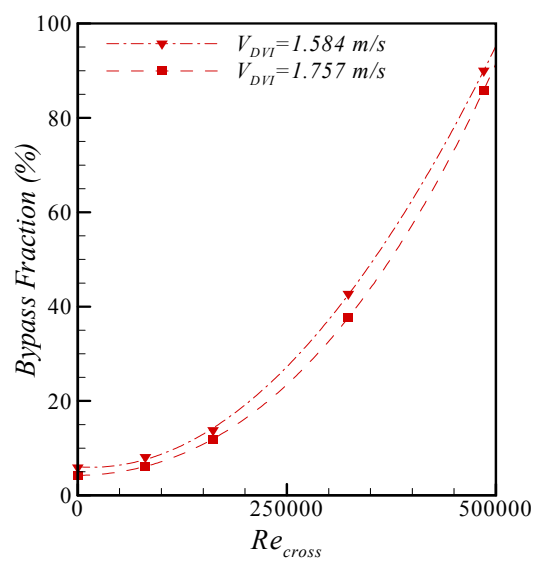

Figure 9: Variation of bypass fraction with Reynolds number of air cross flow.

The loss factor $\mathrm{K}$ is easily obtained by applying the simple Bernoulli equation in the downcomer volume under the assumption that the pressure drop between the DVI nozzle exit and ECBD inlet can be ignored.

$$
K=\left(\frac{V_{D V I}^{2} A_{E C B D}^{2}}{Q_{E C B D}^{2}}-1\right)
$$

Here, $Q_{E C B D}$ is the inflow rate into ECBD which was obtained from the CFD analysis. $A_{E C B D}$ is the cross-sectional area of the ECBD inlet. Figure 10 shows the variation of the $\mathrm{K}$ value with $R e_{\text {cross }}$. Because the variation of the loss coefficient obtained in this study includes the range of the Reynolds number for the steam cross flow expected in the reactor vessel downcomer, it is believed that this result can be directly applied to the existing system analysis code.

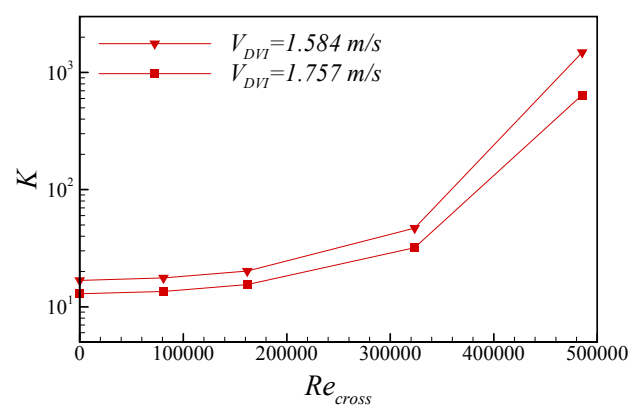

Figure 10: Variation of loss factor with $R e_{\text {cross. }}$ 


\section{Conclusion}

In the present study, CFD analyses were conducted to verify the fraction of flow rate inflowing to the ECBD and to evaluate its performance through a simplified air-water system. The followings conclusions are obtained:

(1) The calculated bypass fractions were well matched with the measured value, which implied the present analysis method is reasonable for this kind of problem.

(2) The flow characteristics from the DVI nozzle to ECBD could be understood. Especially it was found that the open channel flow was dominant at the DVI nozzle as the DVI inlet velocity decreased and the flow velocity at the exit became higher than the average velocity at the DVI inlet, which increased the flow rate into the ECBD more than expected.

(3) When an air flow is considered during ECBD injection, the flow rate into the ECBD is greatly dependent on the air cross flow. Bypass fraction can be predicted through the CFD analysis in terms of cross flow Reynolds number, which can be used for the ECBD models of the system thermal-hydraulic codes.

These results are believed to be conservative because the momentum loss by steam condensation is not considered in an air-water flow.

\section{Acknowledgements}

This work was supported by the Nuclear Safety Research Program through the Korea Radiation Safety Foundation (KORSAFe) and the Nuclear Safety and Security Commission (NSSC), Republic of Korea (Grant No. 1305002).

\section{References}

[1] Korea Hydro and Nuclear Power Inc., Safety Injection System (Chapter 6.3) APR+ Standard Safety Report, Seoul, 2010.

[2] USNRC, Compendium of ECCS Research for Realistic LOCA Analysis, NUREG-1230, R4, Washington D. C. 1998.

[3] Kwon, T.-S., Lee, S.T., Euh. D.J. \& Youn, Y.J., Advanced DVI+, Nuclear Engineering and Technology, 44(7), pp. 727-734. 2012.

[4] Kwon, T.-S., Song, C.-H. \& Baek, W.-P., Advanced DVI for ECC direct bypass mitigation, Nuclear Engineering and Design, 239(6), pp. 1095-1102, 2009.

[5] Ansys Inc., ANSYS CFX-15, 2014.

[6] Ahmad, Z. and Azamathulla, H. Md., Direct solution for discharge in circular free overfall, Journal of Hydrology, 446, pp. 116-120. 2012. 